Research Article

\title{
Modelling the Spatial Distribution Differences of Compulsory Education Resource
}

\author{
Weihong Liang (iD) and Changsong Ma \\ International College, Krirk University, Bangkok 10220, Thailand \\ Correspondence should be addressed to Changsong Ma; lss5241314@163.com
}

Received 9 September 2021; Accepted 30 September 2021; Published 18 October 2021

Academic Editor: Daqing Gong

Copyright (c) 2021 Weihong Liang and Changsong Ma. This is an open access article distributed under the Creative Commons Attribution License, which permits unrestricted use, distribution, and reproduction in any medium, provided the original work is properly cited.

\begin{abstract}
This paper aimed to explore the difference in the spatial distribution of compulsory education resource allocation. Raw data were collected from the 2020 China Statistical Yearbook (county/district level) and Guangxi Province Statistical Yearbook of China. Data analysis was conducted using the entropy method, comprehensive evaluation method, $K$-means clusters analysis, analysis of variance, and spatial statistical analysis (Moran's I index). It was determined that there were significant differences in the spatial distribution of compulsory education. The equilibrium degree to mandatory education resource allocation was divided into three classes: high level, medium level, and low level, and each class presented a spatial aggregation effect in the spatial distribution. Compared with the primary schools, the equilibrium degree of junior secondary school was higher. However, the equilibrium fluctuation of junior secondary schools was more significant among different counties/districts. The equilibrium of educational resources of junior secondary schools in the urban areas was higher than that in the rural areas, but there was no significant difference for the primary school.
\end{abstract}

\section{Introduction}

The equilibrium of educational resource allocation is educational equity's basic premise [1]. It responds to the relationship reaction, measurement, and evaluation of interpersonal scholarly interests [2]. Furthermore, it implies the ideal state and goal of the educational benefit distribution [3]. Compulsory education is the primary stage of education and involves the educational rights of all school-age children [2]. The mandatory education equilibrium resources are related to every family's vital interests [4]. The Chinese government has been committed to promoting a balanced allocation of compulsory education resources [5]. Starting with universal compulsory education and literacy, the Chinese government has been committed to promoting the balanced allocation of mandatory education resources, which gradually form an essential balance to a highquality balance [6]. According to "2019 National Compulsory Education Balanced Development Supervision and Evaluation Work Report," by the end of 2019, there were 23 provinces that had achieved the fundamental equilibrium development of county/district-level compulsory education. 2,767 counties/ districts had passed the national essential equilibrium certification of mandatory education, accounting for $95.32 \%$ of the total ratio. The ones that did not give the accreditation were mainly concentrated in Central China and Western China, known as "former revolutionary base areas, areas inhabited by minority nationalities, remote and border areas, and povertystricken areas" [7]. These counties/districts are severely impoverished areas in China, lagging in education [5]. The social economy and educational development are positively correlated [8]. Although China's economy has developed rapidly, there are severe problems of unbalanced, uncoordinated, and unsustainable development [9]. The eastern economy has developed while the western economy is backward, followed by the wide income gap between the eastern and western residents [10]. Therefore, there are differences in the spatial distribution of China's compulsory education resource allocation. This paper takes the economically backward Guangxi Zhuang Autonomous Region in Southwest China as a research subject to verify the inference. It explores the spatial distribution 
of compulsory education resource allocation in its jurisdiction to provide a theoretical basis for promoting the equilibrium development of mandatory education.

\section{Literature Review}

The former research on the spatial distribution of educational resources mainly included three aspects. Firstly, many scholars found the relationship between the spatial distribution of educational resources and educational equity, such as the spatial distribution of schools of migrant workers accompanying children [11], residential segregation, and campus segregation [12], school zoning and racial segregation [13], the relationship between school emergence and the equity of educational opportunity [14], the relationship between family capital and distance to school [15], the relationship between educational resource transfer and educational equity between different levels of education [16], and the relationship between multiple allocations of educational resources and educational equity [17]. The second is a research theme based on the results of spatial statistical analysis as a basis for the allocation of educational resources. Müller et al. [18] made a model for choosing a school based on the spatial distance, language factors, and transportation modes. Henig [19] built a complex model for choosing schools by the geographic information system (GIS). Some research focused on public and charter schools [20] and school campus network planning and design in a specific area [21]. Thirdly, former researchers have paid more attention to the spatial relationship between educational resources and public facility allocation. Eren et al. [22] found the relationship between schools' spatial distribution and shared bicycles' spatial distribution. Others found that the planning of public transportation routes and the spatial distribution of schools were correlated $[23,24]$. In summary, previous studies have mainly measured the amount of educational resources by the number of schools $[25,26]$.

However, the number of schools and the investment in educational resources were not positively correlated. Furthermore, there has been little focus on the aspect of educational resource indicators. Therefore, the purpose of this paper was to explore the equilibrium degree of educational resource allocation based on the element of educational resource index through spatial statistical analysis.

\section{Research Method}

3.1. Index Selection and Data Acquisition. The educational resource index of this paper was from China's "interim measures for supervision and evaluation of the balanced development of county compulsory education." The firstlevel index refers to compulsory education conditions for running a school and mandatory education faculty. Furthermore, "compulsory education condition for running a school" included 5 second-level indexes: the area of teaching and extra rooms per student $\left(\mathrm{m}^{2}\right)$, the area of sports venues per student $\left(\mathrm{m}^{2}\right)$, the value of teaching equipment per student (Yuan), the number of computers per 100 students (set), and the number of books per student (volume). "Compulsory education faculty" included 3 second-level indexes: teacher-student ratio, the number of teachers with higher academic qualifications per student, and the number of teachers with intermediate and above professional and technical positions per student.

Compulsory education schools generally include primary schools and junior secondary schools. The index data of the two kinds of schools were separately collected and analyzed in the following study. For description, the secondlevel indexes are numbered as A1, A2, A3, A4, A5, A6, A7, and A8 for primary schools and B1, B2, B3, B4, B5, B6, B7, and $\mathrm{B} 8$ for junior secondary schools in the order given in Table 1. We can see all the data from Table 1.

These data came from Guangxi Province Statistical Yearbook 2020 and China Statistical Yearbook (county/ district level) 2020. The compulsory education schools in Guangxi Province were considered as the study subject.

3.2. Methodology. In this paper, the normalization method aims to preprocess the index; the entropy method contributes to calculating the weight of each index. Finally, the weighted geometric average calculated the total evaluation value of the equilibrium of compulsory education resources in 111 counties/districts. The $K$-means clusters classify the entire evaluation value. Finally, we got 3 categories. Commonly used classification methods are hierarchical clustering and $K$ means clustering. The former is suitable for the case where the number of samples is small. But the number of models in this paper is 111 , so the $K$-means clusters are more consistent with the research method of this paper. To verify whether the classification effect is significant, the coefficients of variation of the first-level indicators for the samples of these three categories were calculated separately, and then one-way ANOVA was used to test whether the coefficients of variation of the first-level indicators of these three categories are dif-

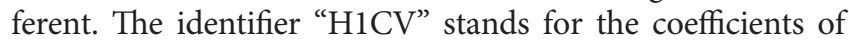

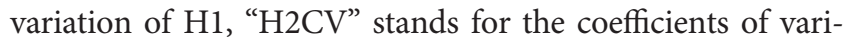
ation $\mathrm{H} 2$, and so on. $\mathrm{H} 1 \mathrm{CV}$ was the sum of $\mathrm{A} 1-\mathrm{A} 5$ coefficients of variation by county, $\mathrm{H} 2 \mathrm{CV}$ was the sum of A6-A8 coefficients of variation by county, and "D1CV" stands for the coefficients of variation of D1, "D2CV" stands for the coefficients of variation D2, and so on. D1CV was the sum of $\mathrm{B} 1-\mathrm{B} 5$ coefficients of variation by county, and D2CV was the sum of B6-B8 coefficients of variation. The coefficients of variation $(\mathrm{CV})$ can reflect the degree of dispersion of various indicators, reflecting the different degrees of educational resources allocation between counties/districts. The larger the $\mathrm{CV}$ value is, the more significant the imbalance of compulsory education resource allocation between counties/districts is. Finally, ArcGIS 10.7 software was used to draw a map of the spatial distribution of mandatory education in Guangxi Province. Global Moran's I index in spatial autocorrelation analysis was used to measure its spatial aggregation characteristics. 
TABLE 1: Index of primary schools and junior secondary schools and descriptive statistics.

\begin{tabular}{lcccccc}
\hline & First-level index & $\begin{array}{c}\text { First-level index } \\
\text { (identifier) }\end{array}$ & $\begin{array}{c}\text { Secondary-level } \\
\text { index(identifier) }\end{array}$ & Min & Max & Mean \\
deviation
\end{tabular}

\section{Data Analysis}

4.1. Entropy Weight of Index. The entropy weight of the index results is given in Table 2. The entropy weight of the first-level indexes $\mathrm{H} 1, \mathrm{H} 2, \mathrm{D} 1$, and D2 was separately 0.238 , $0.762,0.666$, and 0.334 . Therefore, the value of H1/D1 was 0.357 , and the value of $\mathrm{H} 2 / \mathrm{D} 2$ was 2.28 . There was a significant difference in the entropy weight of the index between the primary school and the junior secondary school. According to the principle of entropy method, the equilibrium degree of resources for running a primary school was relatively high, but the equilibrium degree of compulsory education faculty was low. The junior secondary school was exactly the opposite of the primary school.

4.2. Calculation Results of the Comprehensive Evaluation Value. According to the calculation principle, the threshold value is $[0,1]$. The larger the numerical value is, the better the equilibrium degree of educational resource allocation is. Table 3 shows the results of the comprehensive evaluation calculation. The overall level of primary school education resource equilibrium was relatively low (the average value was 0.316), and the difference between rural areas was slight (standard deviation was 0.082). For the junior secondary schools, the equilibrium degree was relatively high (the average value was 4.26). Still, there were significant differences in the equilibrium degree among different rural areas (standard deviation was 0.121).

In Figure 1, there was no significant difference among the average comprehensive value of primary school education resources of different cities. Chongzuo city had relatively more primary school education resources, and the numerical value was 0.378 . Hezhou city had relatively less resources, and the numerical value was 0.233 . On the contrary, the average value of the junior secondary was higher, and the minimum was 0.328 . In a particular city, the trend of the average value of the equilibrium degree of primary and junior secondary education resources was almost the same. Namely, if the average value of primary schools was high, secondary schools were also increased.

The urban area and rural area concepts distinguish each city, and then the average comprehensive value of metropolitan and rural areas was calculated. The results are shown in Figure 2. It shows that there was no significant difference between urban areas and rural areas for primary school. In some cities, the average value in rural areas was higher than that in urban areas, such as Liuzhou, Beihai, Hezhou, and Chongzuo. For junior secondary school, accounting for half of the cities, the average value in the urban areas was higher than that in the rural areas, especially in the towns with more substantial economies, such as Nanning, Liuzhou, Guilin, and Beihai.

On the whole, taking the city as a unit of study, there was no noticeable difference in the distribution of compulsory education resources between cities. There was also no significant difference between the urban and rural areas for a particular city.

Take district/county as a unit for detailed research and get a line chart of the equilibrium value of education resources in the primary and junior secondary schools (see Figure 3). It means that the equilibrium value of every district/country varied, but there were different fluctuations between the two kinds of schools. Compared with primary school, the value of junior secondary school in each district/ county was higher.

4.3. Cluster Analysis. The number of clustering cases of the three categories of the primary school's high, medium, and low levels was separately 23, 40, and 48. For the junior secondary school, they were separately 31,47 , and 33 .

The analysis results of the one-way analysis of variance (ANOVA) from Table 4 show that each variable passed the homogeneity of variance test $(p>0.05)$. There were significant differences between the two groups $(p \leq 0.001)$. Table 5 shows the results of multiple comparisons with the Tukey HSD method, and the $p$ value of 0.516 indicated 
TABle 2: The entropy weight of index.

\begin{tabular}{|c|c|c|c|c|c|}
\hline & & EJ & DJ & \multicolumn{2}{|c|}{ Weight value } \\
\hline \multirow{5}{*}{ H1 } & A1 & 0.995 & 0.004 & 0.029 & \multirow{5}{*}{0.238} \\
\hline & $\mathrm{A} 2$ & 0.989 & 0.011 & 0.072 & \\
\hline & A3 & 0.991 & 0.009 & 0.058 & \\
\hline & A4 & 0.990 & 0.010 & 0.063 & \\
\hline & A5 & 0.998 & 0.003 & 0.016 & \\
\hline \multirow{3}{*}{$\mathrm{H} 2$} & A6 & 0.981 & 0.019 & 0.122 & \multirow{3}{*}{0.762} \\
\hline & A7 & 0.976 & 0.024 & 0.154 & \\
\hline & A8 & 0.926 & 0.074 & 0.486 & \\
\hline \multirow{5}{*}{ D1 } & B1 & 0.987 & 0.013 & 0.086 & \multirow{5}{*}{0.666} \\
\hline & B2 & 0.968 & 0.032 & 0.214 & \\
\hline & B3 & 0.983 & 0.017 & 0.114 & \\
\hline & B4 & 0.972 & 0.026 & 0.192 & \\
\hline & B5 & 0.991 & 0.009 & 0.060 & \\
\hline \multirow{3}{*}{ D2 } & B6 & 0.977 & 0.022 & 0.145 & \multirow{3}{*}{0.334} \\
\hline & B7 & 0.983 & 0.016 & 0.110 & \\
\hline & B8 & 0.988 & 0.012 & 0.079 & \\
\hline
\end{tabular}

TABLE 3: Comprehensive evaluation results.

\begin{tabular}{lcccccrr}
\hline Study section & Min & Max & Mean & Range & Std. deviation & & Quartile \\
\hline Primary school & 0.156 & 0.545 & 0.316 & 0.389 & 0.082 & 0.253 & 0.302 \\
Junior secondary school & 0.085 & 0.749 & 0.426 & 0.664 & 0.121 & 0.381 \\
\hline
\end{tabular}

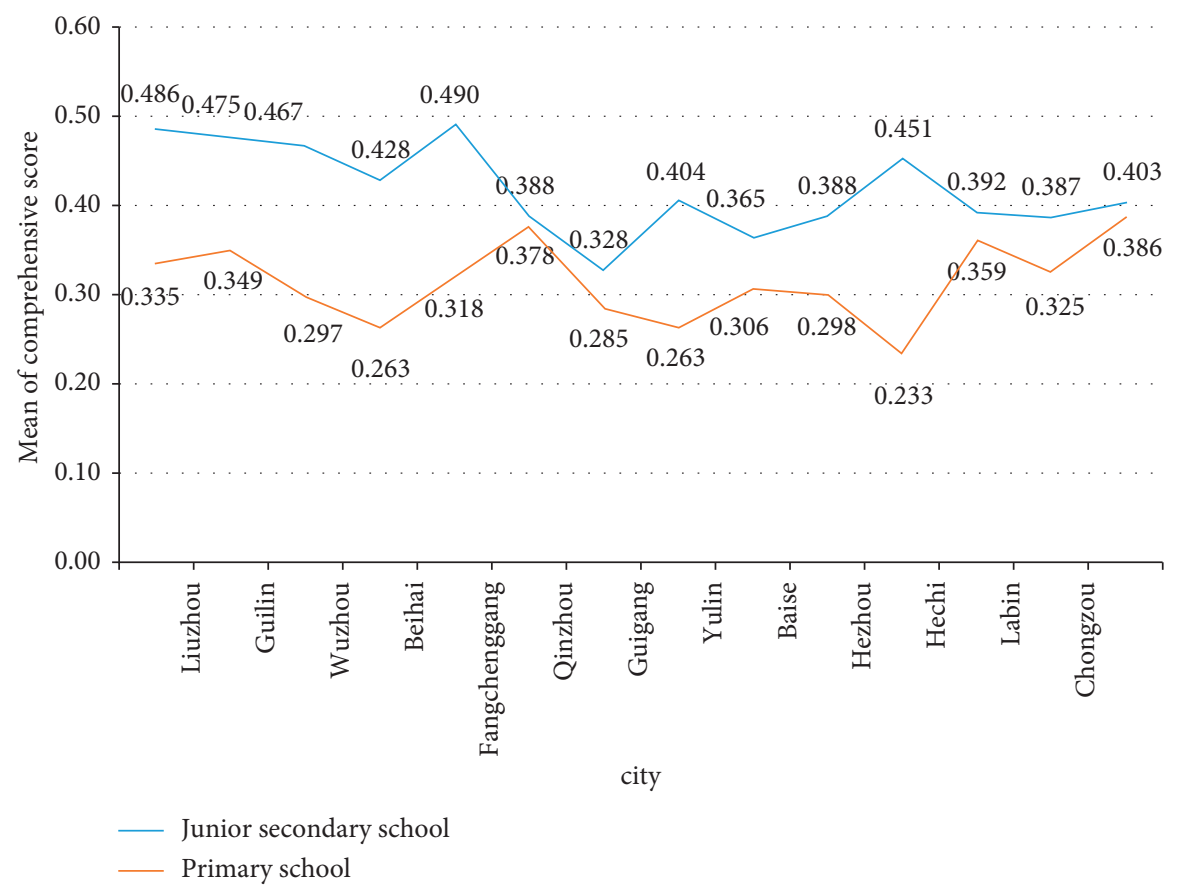

FIGURE 1: Mean of comprehensive evaluation.

that the medium and low groups of $\mathrm{D} 2 \mathrm{CV}$ were not significantly different. The $p$ value $(p \leq 0.002)$ showed that the two compared groups were quite different, and overall, there were significant differences between the groups $(p \leq 0.05)$ except for the middle and low groups of D2CV ( $p>0.05)$, while D2CV was only $3 / 8$ of resource indicators for junior secondary schools. Therefore, it demonstrated spatial differences in the distribution equilibrium of compulsory education resources in the district/county.

4.4. Spatial Distribution Analysis. Figure 4 shows the spatial distribution diagram of the equilibrium degree of compulsory education resources. Generally speaking, the 


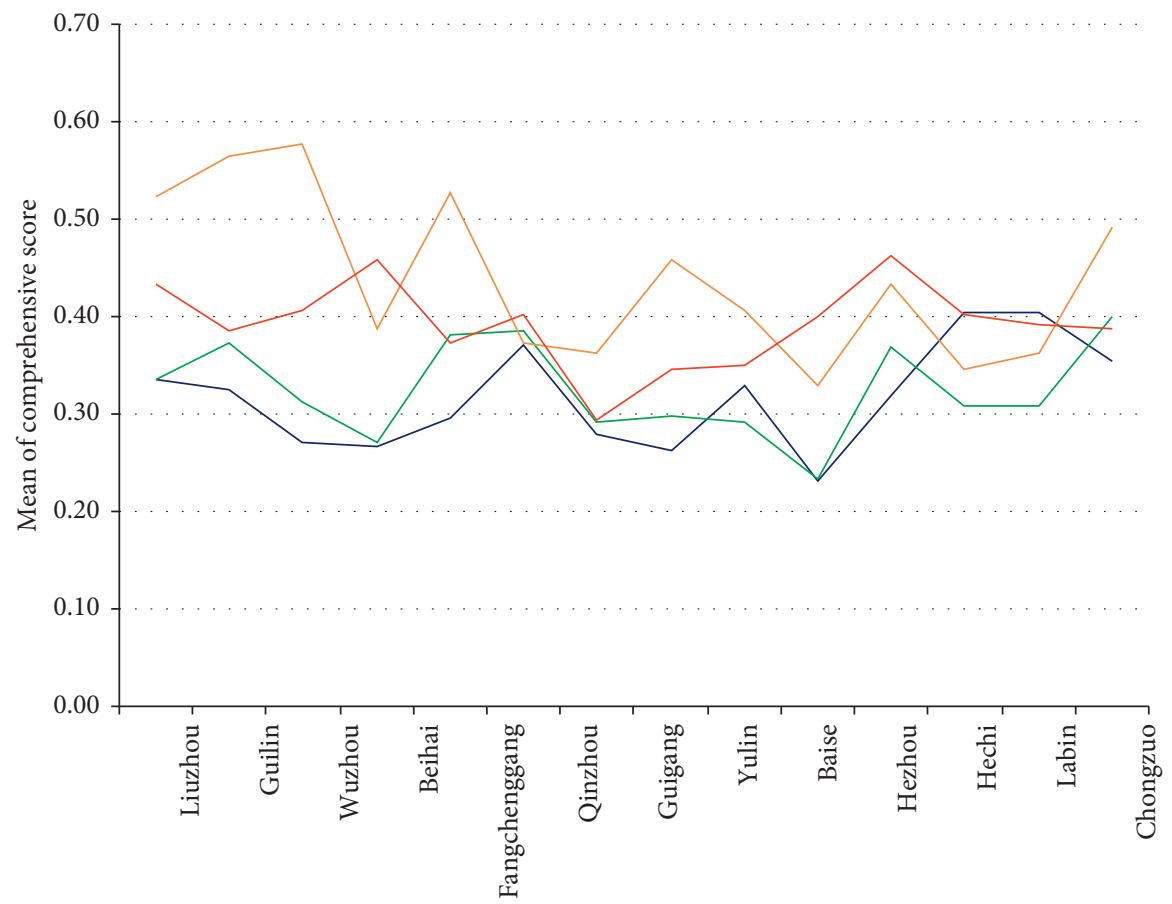

City

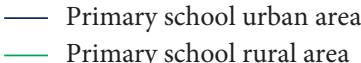

_ Junior secondary school urban area

- Junior secondary school rural area

FIGURE 2: For primary school, the highest urban area score is in Labin (0.405) and rural area is in Chongzuo (0.399), with a difference of 0.006. The lowest urban area score was in Baise (0.232) and the rural area was in Baise (0.310) too, with a difference of 0.078. For junior secondary school, the max urban area score is in Guilin (0.577) and the rural area is in Hezhou (0.463), with a difference of 0.114. The min urban area score is in Hezhou (0.233) and the rural area score is in Qinzhou (0.294), with a difference of 0.061. The trend of the graph and the difference between urban and rural areas show that there is no significant difference in the distribution of educational resources between urban and rural areas.

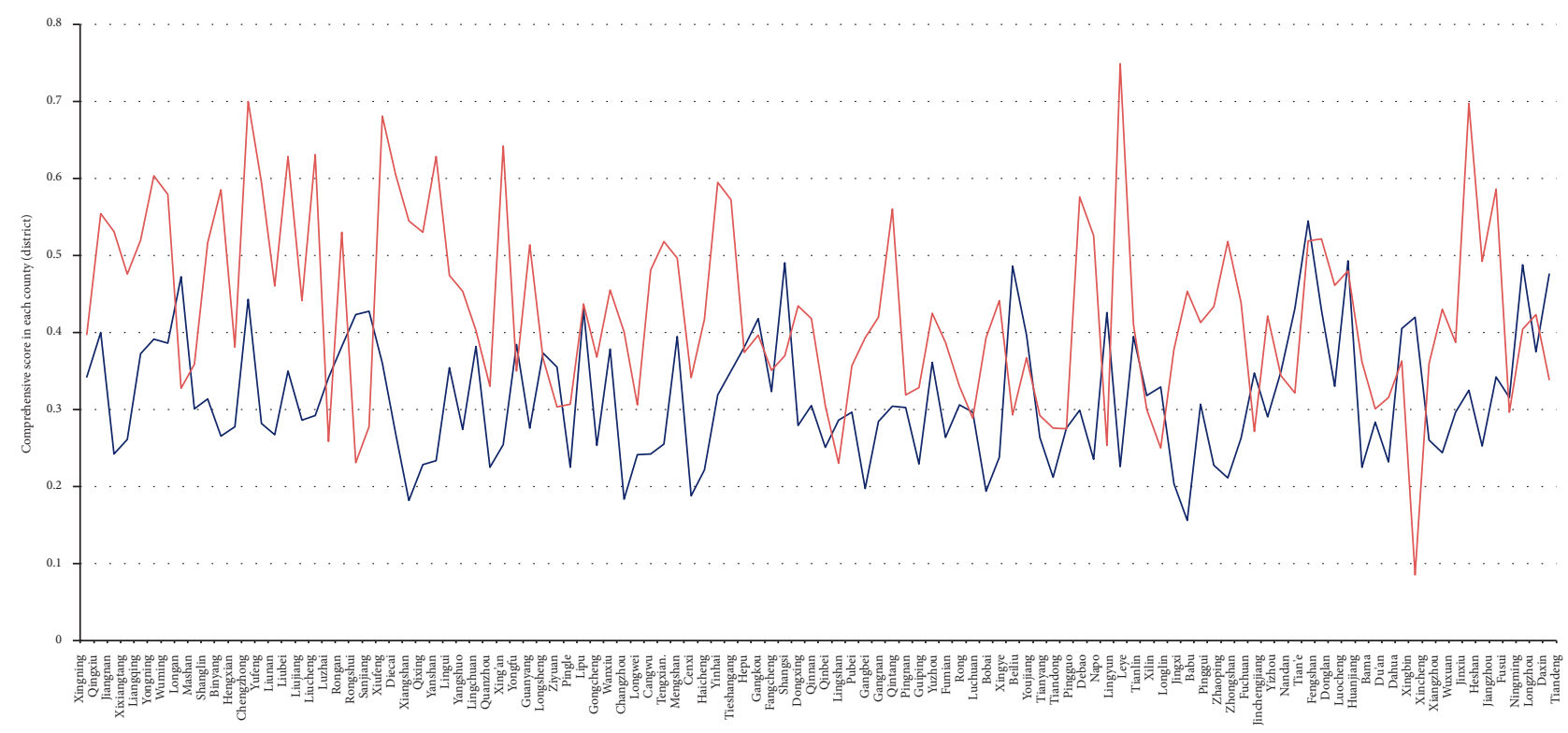

County (district)

Figure 3: Comprehensive score of educational resource balance in each county/district. 
TABLE 4: Significance of homogeneity of variance test and analysis of variance between groups.

\begin{tabular}{lcccc}
\hline Variable & H1CV & H2CV & D1CV & \\
\hline Sig. & 0.091 & 0.183 & 0.216 & 0.627 \\
Sig. & 0.000 & 0.000 & 0.000 & 0.000 \\
\hline
\end{tabular}

TABLe 5: Multiple comparisons with the Tukey HSD method.

\begin{tabular}{lccccc}
\hline \multirow{2}{*}{ Dependent variable } & $(I)$ grouping & $(J)$ grouping & Mean difference $(I-J)$ & \multicolumn{2}{c}{$\begin{array}{c}95 \% \text { confidence interval } \\
\text { Lower bound }\end{array}$} \\
& & & & Sig. & 0.423 \\
Upper bound
\end{tabular}

*The mean difference is significant at the 0.05 level. There were significant differences between the groups $(p=0.05)$ except for the middle and low groups of D2CV $(p>0.05)$, while D2CV was only $3 / 8$ of resource indicators for junior secondary schools. Therefore, it demonstrated spatial differences in the distribution equilibrium of compulsory education resources in the district/county.

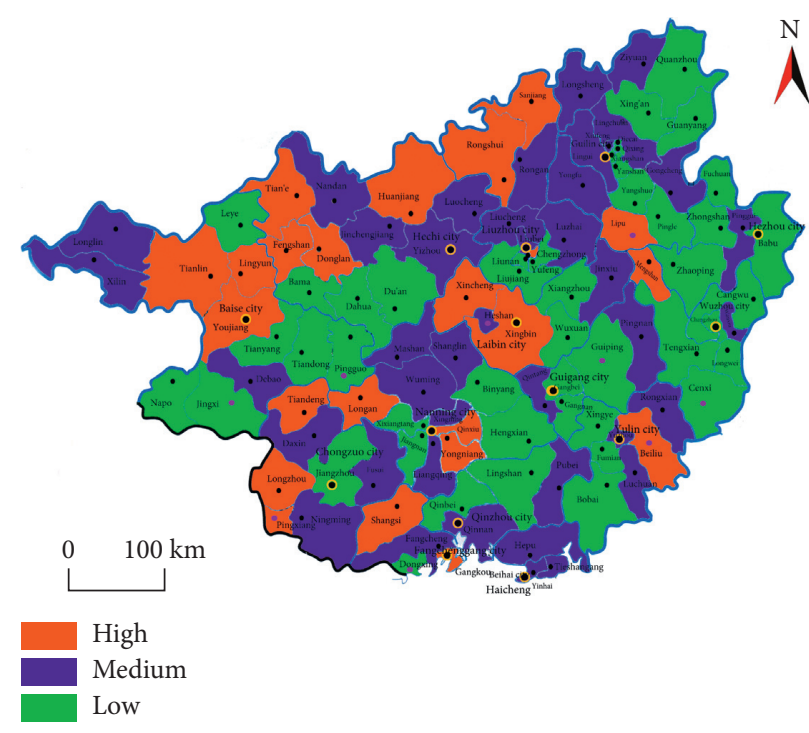

(a)

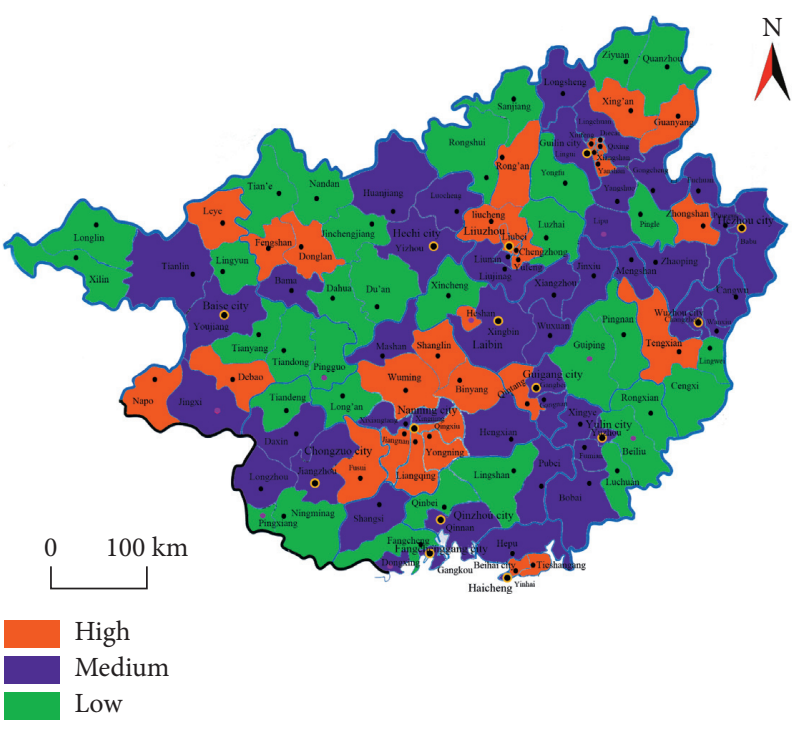

(b)

FIgURe 4: Equilibrium distribution pattern of compulsory education resource allocation. (a) Primary school. (b) Junior secondary school.

counties/districts with the same equilibrium degree formed a spatial aggregation. As shown in Figure 4(a), for the high and middle subgroups of the primary schools, the first aggregation spot was in the northwestern edge of Guangxi Province, forming a continuous band from west to east. The second aggregation spot was in the southwestern Guangxi Province. The spatial distribution pattern approximates a circle with Chongzuo city as the center and Tiandeng County as the radius. For the low subgroup of the primary schools, the first aggregation spot was clustered in the southern marginal counties/districts of Guangxi Province, forming broadband from south to north. The second one centered on Guigang city, going north to Liunan District, south to Bobai County, southwest to Qinbei District, and formed a belt distribution that gradually expanded from north to south. The third one started from Duan County in the northwest and extended to Napo County from east to west along a similar latitude. As shown in Figure 4(b), the high subgroup for the junior secondary schools was concentrated in the urban areas of Nanning city, Liuzhou city, 
TABle 6: Moran's $I$ index.

\begin{tabular}{|c|c|c|c|c|c|c|}
\hline \multirow[b]{2}{*}{ Index name } & \multicolumn{2}{|c|}{ Moran's $I$ index } & \multicolumn{2}{|c|}{$Z$ value } & \multicolumn{2}{|r|}{ Sig. } \\
\hline & $\begin{array}{c}\text { Primary } \\
\text { school }\end{array}$ & $\begin{array}{c}\text { Junior secondary } \\
\text { school }\end{array}$ & $\begin{array}{c}\text { Primary } \\
\text { school }\end{array}$ & $\begin{array}{c}\text { Junior secondary } \\
\text { school }\end{array}$ & $\begin{array}{c}\text { Primary } \\
\text { school }\end{array}$ & $\begin{array}{c}\text { Junior secondary } \\
\text { school }\end{array}$ \\
\hline $\begin{array}{l}\text { Comprehensive } \\
\text { score }\end{array}$ & 0.530 & 0.670 & 9.910 & 12.300 & 0.000 & 0.000 \\
\hline
\end{tabular}

and Guilin city, and gradients of equilibrium extended in all directions from high-, medium-, and low-level equilibrium distributions. Counties/districts close to the urban area had a higher degree of stability in allocating educational resources. In comparison, the ones which were far from the metropolitan area had a lower degree of equilibrium. The 14 cities were adjacent, forming an irregular and interspersed distribution of high, medium, and common areas.

Table 6 shows the results of the spatial correlation analysis. As can be seen, Moran's I estimators of the equilibrium total value of elementary and junior secondary school compulsory education resources were separately 0.533 and 0.670 , which were significantly larger than 0 , and the $Z$ values were separately 9.19 and 12.3 , which were substantially greater than 1.96 . The $p$ values were all less than 0.05. It showed a significant positive correlation between the equilibrium degrees of compulsory education resource allocation and the spatiality in Guangxi counties/districts. There were objective differences in the mandatory spatial distribution of education resources and a significant spatial agglomeration effect.

\section{Conclusions}

This paper takes Guangxi Province of China as the study subject to explore the spatial distribution of compulsory education resource allocation. The sample size is not large enough and is limited to one province. When the sample size is not large enough, it is more difficult to prove the significant correlation of the study content using limited data. Subsequent studies could increase the sample size, expand the study area, or compare data from different provinces, leading to new findings. However, this paper attempts to observe the degree of balance of compulsory education resources from spatial distribution differences and draws research conclusions that may provide some new ideas to promote the mandatory credit of education in the region. The research results were as follows.

Firstly, there was no spatial difference in the distribution of compulsory education resources for the whole city or a particular city. There was also no significant difference between the urban and rural areas for a specific city. However, there were differences in the spatial distribution of compulsory education resource allocation among counties/ districts. Secondly, the spatial equilibrium degree of mandatory education resources allocation in different counties/ districts can be divided into three classes: high level, medium level, and low level, which showed a spatial aggregation effect. Each class formed contiguous distribution in a subcircular or band-like pattern. Thirdly, there were significant differences in the spatial distribution trend of educational resource allocation between primary and junior secondary schools in each county/district. For the urban areas and rural areas, there was no difference in the primary school educational resources.

In contrast, the equilibrium of junior secondary school educational resource allocation showed a gradient distribution, centering on the urban areas and extending to rural areas. China vigorously promoted the balanced development of compulsory education and the information construction to mandatory education. The school-running conditions and faculty of mandatory rural education in China had been effectively guaranteed. However, there were still differences in China's required spatial distribution of education resources, especially in the economically backward central and western regions.

\section{Data Availability}

The data used to support the findings of this study are included in the supplementary information file.

\section{Conflicts of Interest}

The authors declare that they have no conflicts of interest.

\section{Supplementary Materials}

This section includes raw data of the manuscript. (Supplementary Materials)

\section{References}

[1] J. Bengtsson and E. Bolander, "Strategies for inclusion and equality - "norm-critical"," sex education in Sweden, Sex Education, vol. 20, no. 2, pp. 154-169, 2020.

[2] B. D. Lewis and H. T. M. Nguyen, "Assessing the causal impact of compulsory schooling policy in Indonesia," International Journal of Educational Research, vol. 104, Article ID 101693, 2020.

[3] J. Helakorpi, S. Lappalainen, and R. Mietola, "Equality in the making? Roma and traveller minority policies and basic education in three nordic countries," Scandinavian Journal of Educational Research, vol. 64, no. 1, pp. 52-69, 2020.

[4] M. Lachney, A. G. Bennett, R. Eglash, A. Yadav, and S. Moudgalya, "Teaching in an open village: a case study on culturally responsive computing in compulsory education," Computer Science Education, pp. 1-27, 2021.

[5] J. Li, Z. Shi, and E. Xue, "The problems, needs, and strategies of rural teacher development at deep poverty areas in China: rural schooling stakeholder perspectives," International Journal of Educational Research, vol. 99, Article ID 101496, 2020. 
[6] Z. Tianshan, D. Youchao, Y. Runyong, Z. Xiaomei, C. Zhaohui, and L. Xiejing, "Balanced development of compulsory education: cornerstone of education equity," Frontiers of Education in China, vol. 2, no. 4, pp. 469-493, 2007.

[7] Y. Yang and X. Guo, "Universal basic education and the vulnerability to poverty: evidence from compulsory education in rural China," Journal of the Asia Pacific Economy, vol. 25, no. 4, pp. 611-633, 2020.

[8] I. Almås, A. W. Cappelen, K. G. Salvanes, E. Ø. Sørensen, B. Tungodden, and Economics, "Fairness and family background," Politics, Philosophy \& Economics, vol. 16, no. 2, pp. 117-131, 2017.

[9] Y.-H. ZHOU, J. An, Q.-Y. CUI, and H. Science, "The empirical analysis of the balanced development of compulsory education in xinjiang region," DEStech Transactions on Social Science, Education and Human Science, 2017.

[10] C. Zhang, C. Miao, W. Zhang, and X. Chen, "Spatiotemporal patterns of urban sprawl and its relationship with economic development in China during 1990-2010," Habitat International, vol. 79, pp. 51-60, 2018.

[11] D. Zhang, C. Zhou, and W. Xu, "Spatial-temporal characteristics of primary and secondary educational resources for relocated children of migrant workers: the case of Liaoning province," Complexity, vol. 2020, Article ID 7457109, 13 pages, 2020.

[12] I. Ramos Lobato, "School segregation in urban contexts: socio-spatial dynamics and educational inequalities," Urbaria Summaries Series, 2020.

[13] R. Bifulco, H. F. Ladd, and S. L. Ross, "Public school choice and integration evidence from Durham, North Carolina," Social Science Research, vol. 38, no. 1, pp. 71-85, 2009.

[14] C. Donis-Keller, B. O'Hara-Miklavic, and J. C Fairman, "Improving educational opportunity and equity through school district consolidation in Maine," Maine Policy Review, vol. 22, no. 2, pp. 42-54, 2013.

[15] L. T. Green, J. D. Sànchez, and A. J. Castro, "Closed schools, open markets: a hot spot spatial analysis of school closures and charter openings in Detroit," AERA Open, vol. 5, no. 2, pp. 23-39, 2019.

[16] M. Hidalgo-Hidalgo and I. Iturbe-Ormaetxe, "Should we transfer resources from college to basic education?" Journal of Economics, vol. 105, no. 1, pp. 1-27, 2012.

[17] A. Balestrino, L. Grazzini, and A. Luporini, "A normative justification of compulsory education," Journal of Population Economics, vol. 30, no. 2, pp. 537-567, 2017.

[18] S. Müller, S. Tscharaktschiew, and K. Haase, "Travel-to-school mode choice modelling and patterns of school choice in urban areas," Journal of Transport Geography, vol. 16, no. 5, pp. 342-357, 2008.

[19] J. R. Henig, "Geo-spatial analyses and school choice research," American Journal of Education, vol. 115, no. 4, pp. 649-657, 2009.

[20] S. Farmer, C. D. Poulos, and A. Baber, "Challenging the market logic of school choice: a spatial analysis of charter school expansion in Chicago," Journal of Urban Affairs, vol. 42, no. 4, pp. 511-533, 2020.

[21] S. Müller, K. Haase, and F. Seidel, "Exposing unobserved spatial similarity: evidence from German school choice data," Geographical Analysis, vol. 44, no. 1, pp. 65-86, 2012.

[22] E. Eren, V. E. Uz, and Society, "A review on bike-sharing: the factors affecting bike-sharing demand," Sustainable Cities, vol. 54, pp. 101-116, 2020.
[23] H.-Y. Li, W. Xu, Y. Cui, Z. Wang, M. Xiao, and Z.-X. Sun, "Preventive maintenance decision model of urban transportation system equipment based on multi-control units," IEEE Access, vol. 8, pp. 15851-15869, 2019.

[24] A. I. Moreno-Monroy, R. Lovelace, and F. R. Ramos, "Public transport and school location impacts on educational inequalities: insights from São Paulo," Journal of Transport Geography, vol. 67, pp. 110-118, 2018.

[25] A. Awaga, W. Xu, L. Liu, Y. Zhang, and Management, "Evolutionary game of green manufacturing mode of enterprises under the influence of government reward and punishment," Advances in Production Engineering, vol. 15, no. 4, 2020.

[26] H. Wen, Y. Zhang, and L. Zhang, "Do educational facilities affect housing price? An empirical study in Hangzhou, China," Habitat International, vol. 42, pp. 155-163, 2014. 